http://dx.doi.org/10.1590/1678-4162-8346

Arq. Bras. Med. Vet. Zootec., v.68, n.2, p.345-352, 2016

\title{
Aquisição de imunidade passiva em cabritos alimentados com colostro de cabras com e sem mastite
}

\author{
[Immunity of procurement in passive kids fed colostrum from \\ goats with and without mastitis]

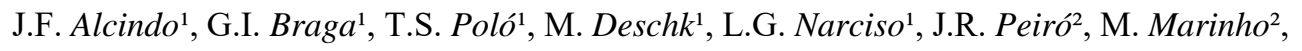 \\ L.C.N. Mendes ${ }^{2}$, F.L.F. Feitosa ${ }^{2}$ \\ ${ }^{1}$ Aluno de pós-graduação - Faculdade de Medicina Veterinária de Araçatuba - Unesp - Araçatuba, SP
${ }^{2}$ Faculdade de Medicina Veterinária - Araçatuba - Unesp - Araçatuba, SP
}

RESUMO

O objetivo deste trabalho foi avaliar a transferência de imunidade passiva de cabras, que pariram com mastite, para seus respectivos cabritos. Os animais foram distribuídos em dois grupos, a saber: grupo 1 (GI), constituído por cabritos, filhos de cabras sem isolamento microbiológico em ambas as glândulas mamárias, e grupo 2 (GII), composto por cabritos, filhos de cabras com resultado positivo à lactocultura, em pelo menos uma das glândulas mamárias. Foram coletadas amostras de colostro e sangue à parição, bem como às 24 e às 48 horas após o parto/nascimento. O diagnóstico e o monitoramento da mastite nos animais foram realizados por meio do California Mastitis Test (CMT), contagem de células somáticas e isolamento microbiológico. A proteína total foi mensurada pelo método do biureto, e as concentrações de imunoglobulina A ( $\operatorname{IgA}$ ), imunoglobulina G (IgG), transferrina, albumina e haptoglobina por meio da eletrofoerese em gel de poliacrilamida contendo dodecil sulfato de sódio (SDS-PAGE). Os agentes mais isolados na cultura microbiológica foram os Staphylococcus coagulase negativa. Não houve diferença significativa $(\mathrm{P}<0,05)$ entre os valores médios de imunoglobulina $\mathrm{G}(\mathrm{IgG})$ nos cabritos provenientes de cabras com mastite quando comparados aos recém-nascidos oriundos de cabras livres de infecções intramamárias. Da mesma forma, a atividade de gamaglutamiltransferase (GGT) não mostrou diferença entre os grupos em todos os momentos avaliados. A ingestão de colostro decorrente de cabras com mastite não causou falha na transferência de imunidade passiva nos respectivos conceptos.

Palavras-chave: imunoglobulinas, lactocultura, Staphylococcus coagulase negativa, transferência de imunidade passiva

\begin{abstract}
The aim of this study was to evaluate the transfer of passive immunity goats kidded with mastitis to their kids. The animals were divided into two groups, namely: Group 1 (GI) containing kids, sons of goats without microbiological isolation in both mammary glands, and Group 2 (GII), composed of kids, sons of goats with positive result to lactoculture in at least one of mammary glands. Colostrum samples and blood were collected after delivery, 24 and 48 hours after delivery / birth. The diagnosis and monitoring of mastitis in animals were performed using the California Mastitis Test (CMT), somatic cell count and microbiological isolation. Total protein was measured by the biuret method, and the concentrations of immunoglobulin $A$ (IgA), immunoglobulin $G(\mathrm{IgG})$, transferrin, albumin and haptoglobin through eletrofoerese polyacrylamide gel containing sodium dodecyl sulfate (SDS-PAGE). The agents most isolated in microbiological culture were coagulase-negative Staphylococcus. There was no significant difference $(p<0.05)$ between the acquisition of immunoglobulin $G(\mathrm{IgG})$ in goats from goats with mastitis compared to infants originating free goat mammary infections. Similarly the gamma glutamyl transferase (GGT) was equal in the comparison between groups in all evaluated moments. The colostrum intake resulting from goats with mastitis caused no failure in the passive transfer of immunity in their fetuses.
\end{abstract}

Keywords: Immunoglobulins, lactocultura, Staphylococcus coagulase negative, passive transfer

Recebido em 7 de abril de 2015

Aceito em 15 de novembro de 2015

E-mail: jefferson.alcindo@yahoo.com.br 


\section{INTRODUÇÃO}

A fase de recém-nascido compreende o período que se estende desde o nascimento até o $28^{\circ}$ dia pós-nascimento para bezerros, cabritos, cordeiros e potros. É nesse período que o animal depende da proteção imune colostral para a manutenção de sua saúde, antes que haja produção endógena de imunoglobulinas (Feitosa, 2014).

O'Brien e Sherman (1993) sugeriram que valores de $1200 \mathrm{mg} / \mathrm{dL}$ de IgG no soro devem ser alcançados em cabritos recém-nascidos para assegurar boa saúde e boas taxas de sobrevivência até o desmame.

Alguns métodos têm sido usados para o diagnóstico da falha de transferência de imunidade passiva (FTIP) em ruminantes. De acordo com Feitosa et al. (2001), as determinações das concentrações séricas de proteína total, das frações beta e gamaglobulinas e das imunoglobulinas $\mathrm{G}$ e $\mathrm{M}$, bem como da atividade enzimática da gamaglutamiltransferase (GGT), mostram-se eficientes para o reconhecimento de animais que apresentam falha na transferência de imunidade passiva. Proteínas como haptoglobina, glicoproteína ácida, amiloide sérica A e albumina podem ser utilizadas como indicadores valiosos de inflamação nessa espécie (Ceciliani et al., 2012).

Em animais recém-nascidos, a elevação de enzimas como fosfatase alcalina (FA) e GGT nem sempre é de origem hepática, sendo mais provável que seja oriunda da ingestão colostral (Thompson e Pauli, 1981). Portanto, devido ao baixo custo e a sua rápida execução, a determinação da atividade sérica da GGT pode ser boa indicadora na identificação de caprinos com falha de transferência de imunidade passiva (FTIP) (Silva et al., 2007).

Há indícios de que a microbiota intestinal possa influenciar a absorção de macromoléculas, tais como as gamaglobulinas. Esse fato foi evidenciado por James et al. (1981), que relataram diminuição na absorção de $\operatorname{IgG}$ em bezerros que tiveram inoculação bacteriana em seus segmentos intestinais. Entretanto, há poucos estudos sobre a contaminação bacteriana no colostro e seu impacto potencial na transferência de imunidade passiva e saúde neonatal (Fecteau et al., 2002).
O presente estudo teve como objetivo avaliar a transferência de imunidade passiva em cabritos provenientes de cabras com diagnóstico de mastite, no pós-parto imediato, ao longo das primeiras 48 horas de vida.

\section{MATERIAL E MÉTODOS}

Foram utilizadas 20 fêmeas caprinas das raças Saanen e Pardo Alpina, em fase puerperal, provenientes de propriedade localizada no município de São José do Rio Preto, estado de São Paulo. Foram avaliados, também, 20 cabritos machos, filhos das respectivas cabras, ao longo das 48 horas de vida. Os animais foram alocados nos seguintes grupos:

grupo 1 (G1): constituído por 12 cabritos, filhos de cabras sem isolamento microbiológico em ambas as glândulas mamárias;

grupo 2 (G2): composto por oito cabritos, filhos de cabras com isolamento microbiano em pelo menos uma das glândulas mamárias.

Os cabritos foram retirados de suas mães imediatamente após o nascimento e alimentados por meio de recipiente de plástico, pequeno e de boca larga, semelhante a um balde, com os colostros de suas mães, tratados termicamente a uma temperatura de $56^{\circ} \mathrm{C}$ por um período de tempo de aproximadamente 30 minutos. O fornecimento de colostro e leite, correspondente à ordenha das duas metades mamárias e na quantidade relativa a $10 \%$ do peso vivo, era feito duas vezes ao dia, uma no período da manhã e outra à tarde, durante todo $o$ período experimental. Outros cuidados habituais recomendados para o período pós-parto também foram realizados no período.

As amostras de colostro provenientes das metades mamárias das fêmeas caprinas recémparidas foram obtidas por ordenha manual logo após a parição, bem como às 24 e às 48 horas pós-parto. Para tanto, as glândulas mamárias e os tetos eram higienizados de acordo com os padrões recomendados em boletim da International Dairy Federation (1981). Após antissepsia, os três primeiros jatos de colostro eram desprezados em recipiente de fundo escuro, e uma amostra de $5 \mathrm{~mL}$ de cada metade mamária foi coletada em um tubo do tipo Falcon estéril, de $50 \mathrm{~mL}$, na posição horizontal, para evitar 
contaminação. Essas amostras foram congeladas a $-20^{\circ} \mathrm{C}$ imediatamente à sua obtenção e encaminhadas para realização de exame microbiológico. Depois de descongeladas, foram semeadas em meio de ágar-sangue de equino desfibrinado e MacConkey e incubadas à temperatura de $37^{\circ} \mathrm{C}$ em atmosfera de anaerobiose e microaerofilia em estufa bacteriológica, por um período não inferior a 72 horas.

As leituras foram realizadas diariamente, após 24, 48 e 72 horas de incubação, quando se observavam as características macromorfológicas das colônias. Consideraramse como positivas as culturas que apresentaram crescimento de pelo menos três colônias idênticas em um mesmo repique da amostra em meio de cultura. Posteriormente, usando amostras provenientes das colônias, foram realizados esfregaços corados ao Gram, para análise das características micromorfológicas dos microrganismos, prosseguindo-se com os testes bioquímicos para identificação do agente de acordo com o protocolo preconizado por Quinn et al. (1994).

A contagem de células somáticas (CCS) foi realizada no leite das cabras imediatamente após o parto, bem como às 24 e às 48 horas, utilizando-se um contador de células somáticas portátil (DeLaval cell counter DCC, DeLaval ${ }^{\circledR}$, Suécia). Uma amostra representativa de cada metade mamária (MIX) foi coletada em tubo Falcon estéril com $15 \mathrm{~mL}$ de capacidade.

Assim como feita na CCS, a avaliação do CMT foi realizada até às 48 horas pós-parição, entretanto $\mathrm{o}$ procedimento foi efetuado nas metades mamárias, individualmente. Para tanto, adicionou-se detergente aniônico neutro (Reagente CMT, Fatec Indústria de Nutrição e Saúde Animal Ltda., Brasil). De acordo com a intensidade, a reação foi classificada em: negativa (0), leve (1), moderada (2) e intensa (3) (Fonseca e Santos, 2000). O resultado foi considerado como positivo quando as secreções lácteas apresentassem reações acima do escore um (1).

As amostras de sangue foram obtidas dos cabritos neonatos por meio de punção da veia jugular, utilizando sistema a vácuo, em um tubo siliconizado, com o uso de agulha para múltiplas coletas $(25 \mathrm{~mm}$ X $8 \mathrm{~mm})$ do sistema Vacutainer ${ }^{\circledR}$ (Vacutainer, Bencton Dickinson, Franklin Lakes, USA). Após as coletas, as amostras foram levadas ao laboratório, sob refrigeração. Em seguida, depois da retração do coágulo, foram centrifugadas a $1000 \mathrm{x} \mathrm{g}$, durante 10 minutos. Posteriormente à centrifugação, o soro foi aliquotado em microtubos com capacidade de $1,5 \mathrm{~mL}$ e congelados a $-20^{\circ} \mathrm{C}$ para a posterior mensuração das proteínas de fase aguda e da GGT.

A determinação da imunoglobulina $G$ e das proteínas de fase aguda foi realizada no soro sanguíneo de cabritos neonatos pela técnica SDS-PAGE, proposta por Laemmli (1970). As frações foram mensuradas por meio de um programa computadorizado (Image Quant TL GE healthcare, versão 7, Buckinghamshire, UK). Como referência, foi utilizada uma solução marcadora (Sigma, St. Louis, MO, USA ) com diferentes pesos moleculares de amplo e estreito espectro e foram avaliadas cinco frações proteicas: imunoglobulina A, transferrina, albumina, imunoglobulina $\mathrm{G}$ e haptoglobina.

As análises bioquímicas foram realizadas em analisador bioquímico semiautomatizado (Celm, SB-190, Barueri, São Paulo, Brasil). A proteína total dos soros sanguíneos foi determinada pelo método do biureto, utilizando-se reagentes comerciais (Labtest, Diagnóstica, Lagoa Santa, Minas Gerais, Brasil ) (Strufaldi, 1987) em comprimento de onda adequado para o teste.

Determinou-se a atividade da gamaglutamiltransferase (GGT) de acordo com o método cinético colorimétrico recomendado pela "International Federation of Clinical Chemistry" (IFCC), usando kit comercial para GGT (Labtest, Diagnóstica, Lagoa Santa, Minas Gerais, Brasil), segundo técnica modificada de Szasz (1969).

As variáveis foram testadas quanto à normalidade pelo teste de Kolmogorov-Sminov e quanto à homocedasticidade pelo teste de Bartlett (quando necessário), seguidos por ANOVA com medidas repetidas ou Friedman com comparações múltiplas de Tukey ou Dunn, respectivamente, para verificar o efeito do tempo dentro do mesmo grupo. Para verificar diferenças entre os grupos, foi utilizado teste T não pareado ou Mann-Whitney. As correlações foram realizadas pelos testes de Pearson ou Spearman. 
Todas as análises foram realizadas em programa estatístico específico (GraphPad Prism Software Inc., v.6.0, San Diego, CA), considerando as diferenças significantes a $5 \%$ de probabilidade.

Todos os procedimentos experimentais foram aprovados pela Comissão de Ética no Uso Animal (CEUA), sob protocolo de número 201301450 .

\section{RESULTADOS E DISCUSSÃO}

Os valores observados na CCS neste estudo não corroboram os relatados por Moreno-India et al. (2012), que encontraram valores superiores na primeira hora pós-parto $\left(3.703 \times 10^{3}\right.$ células $\left./ \mathrm{mL}\right)$ em animais sem infecções intramamárias. Romero et al. (2013) também encontraram valores altos na CCS realizada no período pósparto. A análise dos resultados obtidos demonstrou que houve diferença entre os grupos apenas no momento 48 horas (Tab. 1). Na comparação entre os momentos de um mesmo grupo não foi observada diferença significativa.

Em estudo recente, McDougall et al. (2010) encontraram valores médios de $6.000 \times 10^{3}$ células $/ \mathrm{mL}$ na CCS de cabras com mastite no período logo após o parto; entretanto, a análise feita em glândulas livres de infecções revelou resultados semelhantes ao presente estudo, com valores menores que 1.000 células x $10^{3} / \mathrm{mL}$.

Os resultados reportados pela literatura demostram valores bem mais elevados do que os do atual trabalho. A maioria desses trabalhos utilizou o método fluro-óptico para a contagem de células somáticas, diferentemente do que foi usado no presente experimento. Berry e Broughan (2007), em pesquisa comparando o uso do DCC com a microscopia direta (MD), que é o método de referência para contagem celular de leite de cabra, obtiveram correlação positiva entre esses métodos.

É importante ressaltar que alguns fatores relacionados aos animais, ao manejo, ao ambiente, à localização geográfica e à sazonalidade podem interferir diretamente na CCS de animais dessa espécie, o que pode justificar a discrepância nos valores encontrados por outros autores.

Tabela 1. Valores médios $(\overline{\mathrm{X}})$ e desvios-padrão (S) da contagem de células somáticas (CCS x $\left.10^{3} / \mathrm{mL}\right)$ em amostras de colostro e leite de cabras sem isolamento microbiológico (GI, $n=12$ ) e cabras com isolamento microbiológico (GII, $\mathrm{n}=8)$, à parição $(0 \mathrm{~h})$, às 24 e às 48 horas pós-parto

\begin{tabular}{cccc}
\multirow{2}{*}{ Grupo } & \multicolumn{3}{c}{$\operatorname{CCS}(\overline{\mathrm{X}} \pm \mathrm{S})$} \\
\cline { 2 - 4 } & $0 \mathrm{~h}$ & $24 \mathrm{~h}$ & $48 \mathrm{~h}$ \\
\hline I & $548,66 \pm 841,01 \mathrm{Aa}$ & $869,66 \pm 879,72 \mathrm{Aa}$ & $878,91 \pm 1190,08 \mathrm{Aa}$ \\
II & $708,25 \pm 508,48 \mathrm{Aa}$ & $1340,00 \pm 1086,71 \mathrm{Aa}$ & $1660,25 \pm 1051,05 \mathrm{Ba}$ \\
\hline
\end{tabular}

Médias seguidas de letras distintas, maiúscula na coluna e minúscula na linha, diferem entre si $(\mathrm{P}<0,05)$.

O teste CMT foi feito em 20 animais de ambos os grupos logo após o parto. No GI, observou-se que 14 amostras apresentaram escore zero (0), três destas com escore um (1), enquanto os escores dois (2) e três (3) foram atribuídos a dois e cinco animais, respectivamente. No GII, duas amostras não apresentaram reação, representadas pelo escore zero (0); contudo, três indicaram escore um (1), e quatro e sete amostras de colostro foram correlacionadas aos escores dois (2) e três (3), respectivamente.

Houve associação entre resultado positivo no teste CMT e presença de isolamento microbiológico nas amostras de colostro analisadas imediatamente após o parto $(\mathrm{P}=0,01)$.
Em pesquisa semelhante, McDougall et al. (2010) encontraram sensibilidade e especificidade moderada para o teste na detecção de infecções intramamárias em cabras nos primeiros 10 dias pós-parto. Os autores consideram que esse teste pode ser utilizado como método de triagem nos primeiros dias de lactação, na identificação de cabras com níveis elevados de células somáticas.

Das amostras que foram positivas à lactocultura, apenas uma apresentou alterações macroscópicas, representada, nesse caso, pela presença de grumos. Os Staphylococcus coagulase negativa $(\mathrm{SCN})$ estiveram presentes 
em todos os cultivos microbiológicos realizados, e o percentual de isolamento foi de $22,5 \%$.

A proteína plasmática total ( $\mathrm{PPT}$ ) dos animais do GI foi menor ao nascimento, elevando-se a partir das 24 horas. No GII, os valores de PPT no momento zero hora não diferiram significativamente daqueles avaliados às 24 horas, porém foram menores que os obtidos às 48 horas (Tab. 2). Os baixos índices de PPT ao nascimento são justificados pela pequena quantidade de IgG sérica nesses animais, que tende a se elevar após a ingestão do colostro, como foi observado ao longo das 48 horas.

Algumas pesquisas têm sido realizadas a fim de se estabelecerem valores de referência para IgG em cabritos. No trabalho em discussão, não se constataram diferenças entre os grupos ao longo dos momentos avaliados. Contudo, denotaram-se diferenças estatísticas entre os valores obtidos logo após o nascimento, por serem menores, em relação àqueles observados às 24 e às 48 horas de vida, nos recém-nascidos de ambos os grupos. Esse fato demonstra a dependência do colostro para aquisição de imunidade pelo recém-nascido, visto que uma fração mínima de IgG sérica se faz presente ao nascimento, não sendo capaz de fornecer-lhe proteção. A presença de mastite nas fêmeas não interferiu significativamente na transferência de imunidade para os cabritos, uma vez que a média de concentração de $\operatorname{IgG}$ em ambos os grupos está de acordo com os valores indicados por O'Brien e Sherman (1993), de $1.200 \mathrm{mg} / \mathrm{dL}$, para assegurarem saúde e sobrevivência ao desmame. Além disso, nenhum animal morreu e/ou apresentou alterações nos mais variados sistemas orgânicos durante o período experimental.

Houve correlação entre o teor de PPT com os valores de $\mathrm{IgG}$ às 24 e às 48 horas de vida, tanto no GI quanto no GII, confirmando-a como meio para avaliação da transferência de imunidade passiva (Tab. 4).

Não houve diferença significativa entre a IgA do GI quando comparada com a do GII em todos os momentos avaliados (Tab. 2). Da mesma forma, também não houve diferença entre os valores obtidos ao longo do tempo em ambos os grupos. Esses resultados são justificados pela baixa concentração de IgA no colostro de ruminantes, representando, aproximadamente, $5 \%$ do total de imunoglobulinas presentes (Tizard, 2009). Essa proteína, do ponto de vista clínico, é de pequena relevância para os ruminantes (Johnson et al., 2007).

A albumina, também dosada nos três momentos, mostrou-se mais elevada apenas no momento zero hora, quando comparada ao momento 48 horas no GII. Na comparação entre os grupos, não foi observada nenhuma diferença significativa nos momentos analisados (Tab. 2). Valores menores de albumina são observados após o nascimento em virtude do efeito diluicional, em decorrência do aumento de outras proteínas plasmáticas (Rodriguez et al., 2009).

A transferrina é considerada uma proteína de fase aguda negativa, ou seja, em processos infecciosos os teores dessa proteína tendem a diminuir para minimizar a oferta de ferro para o crescimento bacteriano (Gruys et al., 2005). Não houve diferença significativa entre os valores obtidos de transferrina ao longo dos momentos avaliados tanto no GI quanto no GII, assim como na comparação desses momentos entre os grupos (Tab. 2).

Estudos realizados em bezerros por outros autores mostraram que os valores mais baixos de transferrina são encontrados ao nascimento e tendem a se elevar após a ingestão do colostro; entretanto, os mesmos achados não foram observados neste trabalho (Rocha et al., 2013; Santos, et al., 2013). É possível que, na espécie caprina, essa dinâmica possa ser diferente ou sofrer influência de outros fatores.

Não foi notada diferença entre os grupos quanto à concentração de haptoglobina, assim como na comparação entre os momentos de um mesmo grupo (Tab. 2). Em pequenos ruminantes, a haptoglobina é considerada uma das mais importantes proteínas de fase aguda, e seu aumento pode chegar a 80 vezes em processos inflamatórios (Gonzalez et al., 2008). 
Tabela 2. Média ( $\bar{X})$ e desvio-padrão $(\mathrm{S})$ dos valores séricos de proteína total $(\mathrm{g} / \mathrm{dL})$ imunoglobulina $A$, transferrina, albumina, haptoglobina $(\mathrm{mg} / \mathrm{dL})$ e $\mathrm{IgG}$, em amostras séricas de cabritos, filhos de cabras negativas (GI, $n=12$ ) e positivas à lactocultura (GII, n = 8), ao nascimento (0), às 24 e às 48 horas de vida

\begin{tabular}{cccc}
\hline \multirow{2}{*}{ Fração proteica } & Momento & \multicolumn{3}{c}{ Grupos } & GI \\
\cline { 3 - 4 } Proteína total (g/dL) & $0 \mathrm{~h}$ & $4,16 \pm 0,53 \mathrm{Aa}$ & $4,38 \pm 0,65 \mathrm{Aa}$ \\
& $24 \mathrm{~h}$ & $5,53 \pm 1,06 \mathrm{Ba}$ & $5,85 \pm 1,24 \mathrm{Aba}$ \\
& $48 \mathrm{r}$ & $5,47 \pm 1,92 \mathrm{ABa}$ & $5,72 \pm 1,42 \mathrm{Ba}$ \\
\hline \multirow{2}{*}{ IgA (mg/dL) } & $0 \mathrm{~h}$ & $134,85 \pm 39,42 \mathrm{Aa}$ & $123,69 \pm 32,74 \mathrm{Aa}$ \\
& $24 \mathrm{~h}$ & $130,66 \pm 53,71 \mathrm{Aa}$ & $96,03 \pm 54,07 \mathrm{Aa}$ \\
& $48 \mathrm{r}$ & $131,74 \pm 67,22 \mathrm{Aa}$ & $114,26 \pm 34,03 \mathrm{Aa}$ \\
\hline \multirow{2}{*}{ Transferrina } & $0 \mathrm{~h}$ & $588,07 \pm 130,42 \mathrm{Aa}$ & $624,52 \pm 117,04 \mathrm{Aa}$ \\
(mg/dL) & $24 \mathrm{~h}$ & $569,12 \pm 141,90 \mathrm{Aa}$ & $587,61 \pm 137,00 \mathrm{Aa}$ \\
& $48 \mathrm{r}$ & $579,47 \pm 214,74 \mathrm{Aa}$ & $597,15 \pm 109,29 \mathrm{Aa}$ \\
\hline \multirow{2}{*}{ Albumina (mg/dL) } & $0 \mathrm{~h}$ & $2.571,61 \pm 370,85 \mathrm{Aa}$ & $2.733,75 \pm 439,53 \mathrm{Aa}$ \\
& $24 \mathrm{~h}$ & $2.501,96 \pm 451,51 \mathrm{Aa}$ & $2.329,62 \pm 462,47 \mathrm{ABa}$ \\
& $48 \mathrm{r}$ & $2.444,76 \pm 910,13 \mathrm{Aa}$ & $2.230,01 \pm 364,48 \mathrm{Ba}$ \\
\hline \multirow{2}{*}{ Haptoglobina } & $0 \mathrm{~h}$ & $136,28 \pm 72,79 \mathrm{Aa}$ & $114,15 \pm 49,12 \mathrm{Aa}$ \\
(mg/dL) & $24 \mathrm{~h}$ & $153,45 \pm 36,80 \mathrm{Aa}$ & $141,92 \pm 51,69 \mathrm{Aa}$ \\
& $48 \mathrm{r}$ & $167,07 \pm 85,90 \mathrm{Aa}$ & $133,20 \pm 80,71 \mathrm{Aa}$ \\
\hline \multirow{2}{*}{ IgG (mg/dL) } & $0 \mathrm{~h}$ & $107,22 \pm 38,89 \mathrm{Aa}$ & $99,70 \pm 56,77 \mathrm{Aa}$ \\
& $24 \mathrm{~h}$ & $1.422,77 \pm 679,07 \mathrm{Ba}$ & $1.899,34 \pm 823,64 \mathrm{Ba}$ \\
\hline
\end{tabular}

Médias seguidas de letras distintas, maiúscula na coluna e minúscula na linha, diferem entre si ( $\mathrm{P}<0,05)$.

Os animais do GI apresentaram atividade máxima de GGT sérica $(241,38 \pm 127,47 \mathrm{U} / \mathrm{L})$ após 24 horas do nascimento (Tab. 3). No GII, os teores de GGT também se mostraram mais elevados, às 24 horas, em comparação com os momentos subsequentes. Na comparação entre grupos, não foi possível estabelecer diferença estatística entre os momentos. Esses dados estão de acordo com os achados de Silva et al. (2007), os quais obtiveram valores semelhantes em cabritos que receberam colostro pasteurizado $\left(56^{\circ} \mathrm{C}\right.$ por uma hora $)$.

A atividade da GGT pode servir como indicadora qualitativa da ingestão de colostro pelo recémnascido. $\mathrm{O}$ aumento da atividade sérica dessa enzima está associado à sua ingestão pelo colostro durante as primeiras horas de vida, e não a distúrbios hepáticos (Braun et al., 1982).

Encontrou-se correlação positiva entre a atividade sérica da GGT e o teor de proteína plasmática total (PPT) no momento 24 horas do GI; entretanto, o mesmo fato não foi observado em relação ao GII (Tab. 4). Neste, a correlação só se fez presente no momento 48 horas. Isso pode ter ocorrido em razão da quantidade de animais amostrados, visto que outras informações descritas ao longo do texto levam a crer que os recém-nascidos não foram comprometidos quanto à transferência de imunidade.

Tabela 3. Média $(\overline{\mathrm{X}})$ e desvio-padrão $(\mathrm{S})$ da atividade sérica da gamaglutamiltransferase (GGT) de cabritos que ingeriram colostro e leite, negativos (GI, $n=12$ ) ou positivos (GII, $n=8$ ) ao isolamento microbiológico, desde o nascimento até as 48 horas de vida

\begin{tabular}{cccc}
\multirow{2}{*}{ Grupos } & \multicolumn{3}{c}{ Momentos } \\
\cline { 2 - 4 } & $0 \mathrm{~h}$ & $24 \mathrm{~h}$ & $48 \mathrm{~h}$ \\
\hline \multirow{2}{*}{$\mathrm{I}$} & $38,00 \pm 9,30 \mathrm{Aa}$ & $241,38 \pm 127,47 \mathrm{Ba}$ & $148,63 \pm 79,17 \mathrm{Ca}$ \\
II & $34,75 \pm 12,25 \mathrm{Aa}$ & $322,31 \pm 222,89 \mathrm{Ba}$ & $165,25 \pm 101,80 \mathrm{ABa}$ \\
\hline
\end{tabular}

Médias seguidas de letras distintas, maiúscula na linha e minúscula na coluna, diferem entre si $(\mathrm{P}<0,05)$. 
Aquisição de imunidade...

Tabela 4. Coeficientes de correlação entre os teores de proteína total (PPT), imunoglobulina G (IgG) e gamaglutamiltransferase (GGT) de cabritos desde o nascimento até as 48 de vida

\begin{tabular}{cccccccc}
\multicolumn{2}{c}{ Correlações } & \multicolumn{3}{c}{ Grupo 1} & \multicolumn{3}{c}{ Grupo 2 } \\
\cline { 3 - 8 } & & $0 \mathrm{~h}$ & $24 \mathrm{~h}$ & $48 \mathrm{~h}$ & $0 \mathrm{hr}$ & $24 \mathrm{~h}$ & $48 \mathrm{~h}$ \\
\hline \multirow{2}{*}{ PPT x IgG } & p-valor & 0,6972 & 0,0001 & 0,0021 & 0,4599 & 0,0003 & $<0,0001$ \\
& $r$ Pearson & 0,1513 & 0,8828 & 0,8105 & 0,3068 & 0,9507 & 0,9766 \\
\multirow{2}{*}{ GGT x PPT } & p-valor & 0,3675 & 0,0343 & 0,9779 & --------- & 0,2578 & 0,0067 \\
& $r$ Pearson & 0,2860 & 0,6124 & $-0,0070$ & --------- & 0,4546 & 0,8558 \\
\multirow{2}{*}{ GGT x PPT } & p-valor & --------- & -------- & -------- & 0,8770 & --------- & -------- \\
& $r$ Spearman & --------- & -------- & -------- & $-0,0481$ & --------- & -------- \\
\hline
\end{tabular}

Significativo quando $\mathrm{P}<0,05$.

\section{CONCLUSÕES}

Os cabritos que receberam colostro e leite provenientes de cabras com mastite apresentaram níveis satisfatórios de $\mathrm{IgG}$ para aquisição de imunidade. As proteínas de fase aguda e a atividade sérica da GGT avaliadas não sofreram alterações com a ingestão das secreções lácteas de cabras com mastite.

\section{REFERÊNCIAS}

BERRY, E.; BROUGHAN, J. Use of the DeLaval cell counter (DCC) on goats' milk. J. Dairy Res., v.74, p.345-348, 2007.

BRAUN, D.P.; TAINTURIER, D.; LAUGTER, C. et al. Early variations of blood plasma gamma-glutamyl transferase in newborn calves: a test of colostrum intake. J. Dairy Sci., v.65, p. 2178-2181, 1982.

CECILIANI, F.; CERON, J.J.; ECKERSALL, P.D.; SAUERWEIN, H. D. Acute phase proteins in ruminants. J. Proteomics, v.75, p.4207-4231, 2012.

FECTEAU, G.; BAILLARGEON, P.; HIGGINS, $\mathrm{R}$. et al. Bacterial contamination of colostrum fed to newborn calves in Québec dairy herds. Can. Vet. J., v.43, p.523-527, 2002.

FEITOSA, F.L.F. Semiologia de recém-nascidos ruminantes e equídeos. In: FEITOSA, F.L.F (Ed.). Semiologia veterinária: a arte do diagnóstico. Brasil: ROCA, 2014. p.69-95.
FEITOSA, F.L.F.; BIRGEL, E.H.; MIRANDOLA, R.M.S.; PERRI, S.H.V. Diagnóstico de falha de transferência de imunidade passiva em bezerros através da determinação de proteína total e de suas frações eletroforéticas, imunoglobulinas $\mathrm{g}$ e $\mathrm{m}$ e da atividadeda gama glutamil transferase no soro sangüíneo. Ciênc. Rural, v.31, p.251-255, 2001.

FONSECA, L.F.L.; SANTOS, M.V. Qualidade do leite e controle de mastite. São Paulo: Lemos Editorial, 2000. 175p.

GRUYS, E.; TOUSSAINT, M.J.M.; NIEWOLD, T.A.; KOOPMANS, S.J. Acute phase reaction and acute phase proteins. J. Zhejiang Univ. Sci., v.11, p.1045-1056, 2005.

GONZÁLEZ, F.H.D.; TECLES, F.; MARTÍNEZ-SUBIELA, S. et al. Acute phase protein response in goats. J. Vet. Diagn. Invest., v.20, p.580-584, 2008.

JAMES, R.E.; POLAN, C.E.; CUMMINS, K.A. Influence of administered indigenous microorganisms on uptake of [Iodine-125] TGlobulin in vivo by intestinal segments of neonatal calves. J. Dairy Sci., v.64, p.52-61, 1981.

JOHNSON, J. L.; GODDEN, S. M.; MOLITOR, T. et al. Effects of feeding heat-treated colostrum on passive transfer of immune and nutritional parameters in neonatal dairy calves. J. Dairy Sci., v.90, p.5189-5198, 2007.

LABORATORY methods for use in mastitis work. Bulletin of IDF, v.132, p.1-27, 1981. 
LAEMMLI, U.K. Cleavage of structural proteins during the assembly of the head of bacteriophage T4. Nature, v.227, p.680-685, 1970.

MCDOUGALL, S.; SUPRÉ, K.; DE VLIEGHER, S. et al. Diagnosis and treatment of subclinical mastitis in early lactation in dairy goats. J. Dairy Sci., v.93, p.4710-4721, 2010.

MORENO-INDIAS, I.; SÁNCHEZ-MACÍAS, D.; CASTRO, N. et al. Chemical composition and immune status of dairy goat colostrum fractions during the first $10 \mathrm{~h}$ after partum. Small Ruminant Res., v.103, p.220-224, 2012.

O'BRIEN, J.P.; SHERMAN, D.M. Serum immunoglobulin concentrations of newborn goat kids and subsequent kid survival through weaning. Small Ruminant Res., v.11, p.71-77, 1993.

QUINN, P.J.; CARTER, M.E.; MARKEY, B. Clinical veterinary microbiology. London: WOLFE, 1994. p. 237-242.

ROCHA, T.G.; NOCITI, R.P.; SAMPAIO, A.A.M.; FAGLIARI, J.J. Hemograma e proteínas de fase aguda de bezerros sadios do nascimento aos 30 dias de idade. Pesqui. Vet. Bras., v.33, p.25-31, 2013.

RODRÍGUEZ, C.; CASTRO, N.; CAPOTE, J. et al. Effect of colostrum immunoglobulin concentration on immunity in Majorera goat kids. J. Dairy Sci., v.92, p.1696-1701, 2009.
SANTOS, G.G.F.; DESCHK, M.; SILVA, A.K.G. et. al. Proteinograma sérico de bezerros recém-nascidos alimentados com colostro de vacas com mastite. Braz. J. Vet. Res. Anim. Sci., v.50, p.188-197, 2013.

SILVA, S.L.; FAGLIARI, J.J.; BAROZA, P.F.J. et al. Avaliação da imunidade passiva em caprinos recém-nascidos alimentados com colostro de cabras ou colostro de vacas. Ars Vet., v.23, p.81-88, 2007.

STRUFALDI, B. Prática de bioquímica clínica. São Paulo: Faculdade de Ciências Farmacêuticas da Universidade de São Paulo, 1987. 399p.

SZASZ, G. A kinetic photometric method for serum gamma-glutamyl transpeptidase. Clin. Chem., v.15, p.124-136, 1969.

THOMPSON, J.C.; PAULI, J.V. Colostral transfer of gamma glutamyl transpeptidase in calves. N. Z. Vet. J., v.29, p.223-226, 1981.

TIZARD, I.R. Imunidade no feto e no recémnascido In: TIZARD I.R (Ed.). Imunologia veterinária: uma introdução. Brasil: Elsevier, 2009. p.231-245. 